\title{
An Introduction to Francophone perspectives of learning through work
}

\author{
Laurent Filliettaz (University of Geneva) and Stephen Billett (Griffith University)
}

\section{The concern of learning through practice across cultural traditions}

Learning associated with occupations, and the educational and practice-based experiences that support it, are currently the subject of increased interest and attention in the fields of educational, psychological, sociological, and business management research and teaching. In all these fields, the conditions under which young and mature adults learn outside of educational settings (e.g. schools, colleges, training facilities, universities), in workplaces, have become both relevant to a range of personal, workplace and governmental priorities. Consequently, they are being increasingly researched and evaluated as environments in which to support or augment educational processes associated with the initial development of occupational capacities and their ongoing development across working lives. It follows then, that in different ways across nation states, and particularly those with advanced industrial economies, these settings are becoming seen as being important sites for learning by for governments, employer organisations, professional bodies and unions who are commonly concerned with developing and sustaining competent workforces and workers to meet important personal, workplace and national social and economic goals.

So, distinct policies and practices are being enacted across nation states, often driven by related sets of concerns about preparing graduates for the workplace, sustaining workers capacity across lengthening working lives and engaging educational processes with what happens in workplaces beyond them. However, why is it necessary or helpful to have a book that focuses on Francophone conceptions of learning through work? The idea came from the editors' shared concern that in an increasingly Anglophone world, important perspectives that have their origins outside of that world were largely unknown and, therefore, not contributing to the field of discussion, policy and practice. Filliettaz's overall motivations to bring together a range of Francophone perspectives was premised on concerns that the current body of research dedicated to understanding learning through and for occupational practice appears to be unnecessarily diverse and insufficiently reconciled and integrated. Across various disciplinary, linguistic and cultural contexts, specific methodological, theoretical and organisational avenues have been elaborated in response to the challenges of practice-based learning. Yet, this elaboration has often progressed without reference to the diversity and richness of approaches available across these fields of inquiry. For instance, in the Francophone context of adult and vocational education, many research projects have been undertaken to understand what and how workers learn in the everyday circumstances of their professional practice. Yet, the focus and framing of these enquiries have been diverse and practices in the Francophone world have been labelled in different ways: professional didactics (Pastré, Mayen \& Vergnaud, 2006), ergonomics (Rabardel, 1995), clinics of activity (Clot, 1999, 2008), course of action (Theureau, 2004, 2006), etc. These approaches have 
emerged in different locations of the Francophone area (i.e. France, Canada, Belgium, Francophone Switzerland) and provide distinct, yet potentially complementary responses to the challenges of learning through and for professional practice.

Moreover, these enquiries and their particular perspectives have addressed a wide range of important research questions: how do workers learn from each other in workplaces? How do they understand and conceptualise in its all the work practices they are engaged with? How do they cope with the multiple and often contradictory expectations, requirements and procedures they are facing in workplaces? What sorts of skills and competences are required for contemporary workplaces, characterised by an increasing role of technology, rapid changes and complex tasks? How can the kinds of technical skills and embodied practices required for performance at work be learnt and shared? How can collective activity be transformed through dialogues in work settings? How can workplace simulation be used in training? What sorts of training environments can be designed to assist the learning of the various kinds of knowledge required to become a competent worker? Collectively, since the late 1980s, these research questions have been addressed in a range of occupational fields, such as, the health sector, agriculture, engineering, the food-processing industry, humanitarian organisations and education, to name but some which are represented in this text.

But importantly, the research perspectives adopted in the Francophone context have come to comprise specific traditions, some of which are widely shared internationally, whereas others have acquired a strong visibility only in French-speaking countries, and in some cases only in one country. Together, these traditions, however, have generated and adopted a specific theoretical lens for conceptualising the relations between learning and work. They have also developed a range of concepts and methods through which to investigate how adults learn in, for and through work, and how this learning may be supported and enhanced in training practices. These tools have been widely adopted in those countries, and expertise in their enactment and reporting has been likewise developed. However, these conceptions are largely unknown outside of the Francophone world and are often inaccessible to the English-speaking audience. Yet this audience often ignores traditions that have emerged and developed outside the Anglophone area. Within the English-speaking community, issues related to learning through and for practice have mainly adopted a sociocultural perspective and have been investigated recently under the umbrella of "Workplace learning” (Billett, 2001; Tynjälä, 2008). Hence, Francophone and Anglophone traditions have evolved as parallel elaborations, with little connections and lacking mutual understanding.

Billett's motivation for involvement with this edited monograph came from the realisation that there was a long-standing and particular tradition about learning in, through and for work within Francophone countries that appeared to be largely unrepresented in the Anglophone literature. As with his own work, understandings about learning through work have largely drawn upon traditions, conceptions and theoretical orientations that are strongly shaped by, and represented and privileged in Anglophone literature. Hence, becoming aware by French-speaking colleagues that traditions such as 'professional didactics' and 'ergonomics' are commonly used in the Francophone world revealed a significant gap in this field of enquiry available to any speakers. As it emereges clearly from this volume, across a characteristic feature of this tradition, and in contrast to how learning through work is often referred to in the Anglophone accounts, is to conceptualise learning through practice in its 
own terms and qualities, and not in comparison with what occurs in educational institutions (i.e. references to informal, non-formal education et cetera). Although arising inadvertantly, Inevitably, such approaches generate interest in and focuss attention upon the Francophone traditions that are their genesis, and have fostered, developed and have sustained them despite an increasingly Anglophone-dominated scientific discourse. Not the least of concerns to promote Francophone traditions and perspectives are those associated with the dominance of this academic publications increasingly being through English-language media. Francophone scholars now being pressed to publish in English language journals that are seen as the most prestigious in their fields. However, more than facing the challenge of being pressed into writing in English, French-speaking researchers might experience the press of adopting the kinds of theoretical traditions (i.e. those from the English-speaking world) with which the reviewers and readership of those journals are familiar and comfortable. It is also perhaps understandable in such circumstances, in a quest to have their work published, that a younger generation of Francophone scholars and research students may look to Anglophone theoretical traditions rather than Francophone ones to secure publication.

Consequently, there emerges a risk in this shift to publishing in English and in such journals, and not only for the Francophone traditions but all of those outside English-speaking countries. That risk is about indigenous conceptions, practices and orientations being displaced, not because of lack of merit or worthiness, but because they are not represented in English and/or Anglophone literature and idioms. It also means that these conceptions, practices and representation may become lost or at least be unavailable to the English-reading world, and potentially discarded in their own. For instance, without the efforts of Philipp Gonon (Gonon, 2009b), the contributions of the early German promoter of vocational education Georg Kerschensteiner may well remain unknown and inaccessible to Anglophone audiences. This includes the influence that German models of vocational education had on debates in United States about what should constitute the American approach to vocational education (Gonon, 2009a), for instance. So, there is at least as much merit in explicating the Francophone traditions, practices and approaches to learning through practice.

\section{The genesis of this book project}

The project for this book is to mitigate against any discarding of these Francophone conceptions of learning in and through work, and their traditions and practices through engaging with and elaborating them for English reading audience. Importantly, this engagement and elaboration also serves to assist understand and appraise the particular contributions of the Francophone world to the contemporary discussions about learning through and for work and identify how they might complement or augment traditions and practices from other cultures and traditions. Beyond these specific purposes is a need for the essence of these approaches to be explicated and made available to Anglophone scientific audiences, that which might not otherwise occur.

To secure these aims, the specific contributions to this book: a) describe and discuss theoretical, methodological and practical issues related to learning through practice in the traditions of the Francophone area and compare these with those of other cultural contexts; b) identify conceptual bases, empirical applications and implications of Francophone research on the topic of learning through and for professional practice; c) provide the English-speaking research community with a sound and comprehensive account of the origins and histories of 
these contributions and presentations of recent findings and developments; and d) build the platform for increased collaboration and joint understanding between researchers representing diverse disciplinary perspectives within various cultural contexts. However, there is no claim that the contributions to this book provide an exhaustive accounts of these topics in the Francophone world. They have, instead, been selected as they illustrate perspectives and traditions that have become orthodox within the French-speaking research community and because they can be seen as a fruitful basis for developing a mutual understanding between and across these research traditions.

To realise these objectives and prepare for the book, a collaborative and dynamic set of activities took place over three years. First, most of the selected authors attended an international workshop dedicated to the topic of Learning through work in March 2012 at the University of Geneva. Based on the presentations that took place during this workshop, topics for book chapters were identified and assigned to each author. The group of authors produced draft chapters during autumn 2013 and then met again in Geneva, in February 2014 ${ }^{1}$. The second workshop was dedicated to an in-depth discussion of each chapter and aimed to tease out key ideas laying at the core of Francophone traditions of learning through work. To connect these reflexions to broader considerations coming from Anglophone traditions, four scholars with diverse geographical, cultural and disciplinary backgrounds were invited at the workshop as discussants: Simone Volet (Murdoch University), Geoffrey Gowlland (University of Oslo), Raymond Smith (Griffith University) and Charlotte Wegener (University of Aalborg). The role of discussants was to bring an external perspective on the work discussed and to identify possible connections between cultural traditions on learning through work. After the second workshop, authors and discussants revised, rewrote and refined their chapters during the European spring of 2014. Subsequently, the chapters were reviewed, and further rounds of revisions and editing followed. The outcomes of this process are found in the chapters of this edited monograph.

The contributions of the book are organised under two sections. The first section Conceptualising the links between learning and practice - comprises 7 chapters presenting and illustrating distinct but complementary conceptions that have emerged in Francophone academic fields about the relations between learning and practice, and a commentary chapter. The conceptions on learning are defined and explained by drawing on a range of disciplinary bases (i.e. work psychology, anthropology, vocational didactics and organisational sciences). The second section of the book - Conceptualising the links between training and work comprises 6 chapters dedicated more specifically to the relations between occupational training and work, and a commentary chapter. There is also a summary chapter at the end of this section. The authors of these chapters present theoretical considerations, methodological approaches and empirical findings about how training practices in educational programs and in workplace settings can be effectively based on a fine-grained understanding of work. As noted each section of the book concludes with a critical discussion of the preceding chapters. In each, a scholar with broadly-based international expertise on conceptions of learning in practice discusses and responds to the contributions in the chapters and draws links between these conceptions and the broader literature accessible in the field.

\footnotetext{
${ }^{1}$ The co-editors of this book are grateful to the Swiss National Science Foundation (FNS) for sponsoring the International Exploratory Workshop (grant Nr. IZ32Z0_150894).
} 
As a means of introducing and providing an overview of the contributions of this book some foreshadowing is warranted here.

\section{Mapping the field of Francophone perspectives on learning through work}

An important place to commence is through outlining what are the origins and the peculiarities of the Francophone perspectives on learning through and for work. That is the focus for the following chapter which provides an overview of the field of Francophone research on learning through work and is intended as a platform for presenting a delineation of this field. Entitled Conceptualising and connecting Francophone perspectives on learning through and for work, the chapter commences by presenting a range of research traditions that have secured important places within the French-speaking research community and also explains the disciplinary background underlying these traditions, through identifying key premises and concepts, and specific research and training methods that have emerged in that particular context. Adopting a cultural historical approach, the chapter also attempts to illuminate the specific conceptions of learning these traditions are built upon and have contributed to promote in the French-speaking world. Three research traditions are selected and described by its authors, Laurent Filliettaz, Stephen Billett, Etienne Bourgeois, Marc Durand and Germain Poizat in relation to their distinct historical and cultural backgrounds, and key ideas and methodological focuses: i) Francophone ergonomics and work analysis; ii) language use, in connection to work and learning iii) collective and organisational dimensions to learning through practice.

The first of these three traditions comprises what is referred to Francophone ergonomics and the epistemology of so-called "work analysis". The historical and disciplinary origins of emergence of the Francophone tradition of ergonomics are presented, along with its central concepts, contributions to methods and applications in the field of vocational and professional training. Secondly, the particular tradition of language use in relation to work, training and learning is elaborated. These issues have acquired considerable visibility within Francophone research and have developed into a specific research tradition, which reflects the unique Francophone conceptualisations. An overview of the main research topics that have emerged within this tradition and key contributions to vocational and professional training issues are presented in this chapter. The third tradition is that referring to learning in connection with specific organisational contexts. Here, the social dimensions of learning are foregrounded and contributions from Francophone researchers are illustrated, and their alignment with other research traditions, and particularly those widely disseminated in the Anglophone world. The final section of the chapter draws together a range of ideas which have emerged beyond and across these specific research traditions, and that can be seen as having played an influencing role on the ways questions related with learning through and for work have been addressed in the Francophone world.

\section{Conceptualising the links between learning and practice}

Having set the scene for these traditions through this chapter, it leads into the contributions that comprise the first of the two major sections: entitled Conceptualising the links between learning and practice. 
The first chapter (3) in this section is entitled Stimulating Dialogue at Work: the Activity Clinic Approach to Learning and Development by Laure Kloetzer, Yves Clot and Edwige Quillerou-Grivot. This chapter presents key concepts for what is referred to as the Activity Clinic approach and one of its developmental methodologies, cross selfconfrontation interviews. The Activity Clinic approach is grounded in Vygotskian culturalhistorical psychology. Accordingly, the authors consider individuals' activities as inherently social and mediated by cultural artefacts, which are at the same time used and transformed by individuals who engage with them. This approach, while well-known in the Anglophone world, is also inspired by French ergonomics, with its attention to activity as it is performed by the workers, and by work psychopathology. In short, it is advanced as an interventionist methodology to transform work, primarily as a developmental methodology. The first part of the chapter introduces core concepts of this approach which includes a description of the cross self-confrontation methodology. This description and analysis is supported by data collected during an intervention within the car manufacturing industry, aimed at supporting the prevention of Work-Related Musculoskeletal Disorders (WRMSDs). In the second part, learning and development in this type of developmental intervention is captured and characterised. Learning through work, therefore, is primarily envisioned in relation to development. In this approach, researchers focus primarily on actions to help develop workers' power to act within their professional milieu, on their organisation, and upon themselves. However, a critical analysis of the developmental research process shows that it generates and, indeed, necessitates learning on the part of those workers who are the object of these interventions. In the final section of the chapter, the dynamic character of activity development is highlighted.

Emphasising on learning through different kinds of participation in practice settings, the next chapter (4) - Learning by participating: a theoretical configuration applied to French cooperative day care centres, Gilles Brougère connects two distinct areas and kinds of participation. That is, of early childhood education (particularly for children under the age of three) and also adult education in a framework where there is no explicit educational objective. Using the concepts of participation, community of practice and repertoires of practices, this chapter reports an investigation of the participatory practices within parent-run cooperative day care centres. The findings indicate differences of modalities of participation between the day care centres, with some limitations and obstacles, but full participation with no visible differences between the participation of parents and professionals, in others. These day care centres can be seen as communities of practice, where the shared repertoire of practice is an important aspect with a dynamic of learning for parents, workers and children. The chapter illustrates the development of knowledge-in-practice in relationship to the diversity of the families comprising these parents and their children. It appears from the analysis presented that a shared repertoire arises from a cultural negotiation that is largely implicit and can best be explained in terms of interpersonal or person-to-person relationships, and rarely at the level of the day care centre as a whole. In this way, the norms, values and practices are largely informed and appropriated through interpersonal relationships rather than through the expression of some situational-based mediation. In sum, it is through their participation (whose modes, linked to the affordance of each day care centre, vary) that parents learn and negotiate their practices, and likewise transforming their repertoire of practice. This is also true of workers and children, thereby making parent-run cooperative day 
care centres particularly remarkable kinds of communities of practice with particular learning effects.

An even more micro analysis of how learning arises through practice is advanced in Blandine Bril's chapter entitled Learning to use tools: a functional approach to action. Tooluse here is considered a privileged entry point for understanding the nature of learning through action. The aims of this chapter (5) are two-fold. Firstly, examining the process of individual skill learning from a functional point of view, and, secondly, examining how the context (the "field of promoted action") is organised in ways that can facilitate the learning process. It is held that when engaging in functional goal-directed actions, the actor is not simply directed towards the goal, but rather directed by the goal itself. Thus, it is the work goals to be achieved that specify the demands that must be fulfilled, and in some ways scope of what might be learnt through securing those goals. In the chapter, it is held that functional actions are not specified by bodily movements, as such, but by the ability to solve particular motor problems posed by the environment where the work tasks are conducted. Here, it is suggested that to understand these goal directed activities it is necessary to differentiate amongst between four layers of parameters: i) functional parameters, ii) control parameters, iii) regulatory parameters and iv) movement parameters. The functional parameters specify the task and are independent of the actor. This applies regardless of whether the actor is a human or a non-human or a robot actor. The layer of control parameters specifies the functional parameters and these are able to be controlled by the actors. Finally, the control parameters are set up through different possible strategies that are person dependent. That is, vary amongst actors who engage in different kinds of bodily movements in tool use. The learning process is based on an exploratory activity that progressively drives learners to discover and master the functional parameters of the task. It is proposed that this learning process arises in and through a "field of promoted actions" which organises the experience of learners. Consequently, the tutor's role is in organising the experience of the learners through setting up and securing their engagement in the field of promoted actions and assisting in adjusting this field of promoted actions to the learners' level of skills. So, here though is a highly situationally constrained set of goal directed actions yet which are inevitably enacted in person dependent ways.

We live in a world filled with material objects and, certainly, the workplace and occupational training are no exception proposes Germain Poizat in his chapter (6). Entitled Learning through interaction with technical objects: From the individuality of the technical object to human individuation his chapter proposes that examining the 'beingness' of technical objects within the context of occupational education and training needs to be taken seriously as a contribution to thinking, acting and learning. The claim here is that when objects are freed of their status as mere artefacts - that is, as things having undergone even the slightest human transforming action - and are, instead, granted the status of technical object, their decisive role in work as an expansive activity, as an ongoing process of growth can be understood. Like the Kloetzer et al chapter, his case draws on some precepts from Francophone perspectives, but also uses the concepts of appropriation and individuation in building the case that are drawn from other traditions. The case is advanced through four interrelated discussions. First, assumptions of the enactive approach are presented and how these assumptions differ from objectivist ontology are described. Then, the concepts of mode of existence and beings of technology in order to then explain a specific conception of 
technical objects are examined. Third, the constitutive role of artefacts in learning and development is discussed. Finally, some consequences for educational research are raised in the final section. Throughout, the ineptness of having the subject-object dichotomy is used to claim the heuristic nature of hybridity makes humans beings "technical beings", the necessity to explore seriously the 'beingness' of technical objects, because of the: i) individuation that characterizes the transformation of human activity, ii) the key role of technics in defining standards and training contents, iii) the centrality of appropriation as the fundamental transformation in the activity of actors in training, and iv) the potential value of conceive training design as technical invention. Such a wide-ranging genetic interpretation of the relationship between humans and their environment is proposed as a means to build future adult education provisions that engages with both social and technological transformations and their appropriation in a perspective that takes into account the centrality of individuation.

Philippe Lorino's chapter - Learning as transforming collective activity through dialogical inquiries - also emphasizes human meaning making, albeit as a dialogic process. This chapter (7) holds that learning is an intrinsic aspect of every conscious, purposeful activity in which individuals engage. That activity is viewed as dialogical - activity is addressed through and acquires its meaning from the interacting situation - and mediated by different types of semiotic mediations (e.g. language, tooling, information systems, procedures). All mediations are ultimately held to be referenced to one final mediation: i.e. socially recognizable and meaning-making habits. Also, when unpredicted situations disrupt habits, then multiple and partly invisible inquiries lead to their transformation to allow activity continuation. In this way, activity, habits and inquiries are all proposed as being dialogical and weaving the threads of a collective sense-making narrative. Learning is, thus, defined here as the continuous transformation of habits and of their combination into sensemaking cross-functional narratives through dialogical inquiries. Inquiries can be felicitous, meaning that they succeed in reweaving the threads of collective activity, or infelicitous. One key issue thus is identifying the conditions of felicity. This approach is illustrated by the case of an electricity company. The implementation of an integrated management information system (ERP) disrupted existing professional habits without providing the conditions for felicitous inquiries, leading to an organizational crisis. In the light of this case, it is advanced that a key condition of organizational learning is to view collective activity, not only in its "directly performing" dyadic dimension (e.g. A transforms B), but also in its mediated triadic dimension (e.g. A means C by transforming B). That is, giving due consideration not only to "what people actually do", but also to "what people actually mean by doing what they do", with three mediating dimensions. It is proposed that this approach to organisational requires establishing the adequate communities of practice, to transform professional habits and identities, and communities of process, to redesign cross-functional inquiries and the crossfunctional narrative coherence of processes.

Continuing this focus on work and interactions, Frédérik Matte and François Cooren propose that tensions or contradictions experienced in workplace settings need to be viewed as either something to be resolved individually or as a constitutive aspect that people have to learn to deal with collaboratively. In their chapter (8) - An 'on-the-go' approach to dealing with organizational tensions, they explore the latter perspective through describing how dealing with specific tensions on a daily basis can be conceptualised as an 'on-the-go' approach toward learning (and collaborating). This approach, they hold, is built upon every 
day dialogues in and through work but also foster a process of co-construction of knowledge. Mobilizing what they refer to as ventriloqual perspective on interaction, the chapter identifies and analyzes every day communicative practices (hence, the on-the-go approach) that enables workers in the humanitarian organization Médecins sans Frontières/Doctors Without Borders (MSF) to learn how to deal with a specific tension that arises as being ubiquitous in their discussions. These tensions often arise from the need for an emergency-oriented approach to work whilst adopting a more long-term perspective during the implementation of missions around the world. The authors set out to demonstrate using empirical data how an experienced and an inexperienced MSF member both deal with and learn from such a tension in their daily activities, building on it while simultaneously incarnating it in one interaction at the time through their interactions. Organizational learning (OL) is sometimes envisaged as a communicative achievement. More centrally, the authors claim that organizational learning is occurring subtlety during the everyday mundane interactions that comprise individuals' workbased interactions, implying in the process an evaluation mechanism where the situation itself contributes as a third party to that remaking of the organisation's norms and values and the same time promoting individuals' learning.

Geoffrey Gowlland provides both a summary and an evaluation of the contributions of this section to a discussion on the relations between learning and work. Entitled Discussion: francophone approaches to learning through practice, his chapter (9) discusses six contributions that arise from his reading of the contributions in this section and through drawing parallels and highlighting differing viewpoints across chapters. Gowlland identifies the two notions of 'intentions' and 'tensions' as running through these contributions, and these serve as a starting point to reflect on the significance of the approaches contained in the contributions to this section. He notes, several papers identify tensions as sources of learning in the workplace. The dimension of intentionality meanwhile arises in other contributions, and points to the necessity to understand the actions of individuals with reference to their motivations, goals, and ideas about themselves. These questions are addressed in the context of reflections that tackle three major themes in the theory of practice: 'community', 'environment' (both physical and social), and 'morality' or 'ethics'. He concludes that a commonality in the approach of the papers is that learning is defined as fluid, open-ended, goal- and intention-directed, and a positive outcome of the daily tensions and disruptions of working life.

\section{Conceptualising the links between training and work}

The contributions in the second section of this book commonly focus on links between training and work. That is, the educational dimensions of learning through work.

The first contribution authored by Patrick Mayen directly addresses an essentially Francophone conception and tradition - Vocational Didactics: Work, Learning and Conceptualization. In this chapter (10) he describes and discusses vocational didactics and, in particular, focuses on elaborating on account of one of its principal characteristics: conceptualization in action. Vocational didactics is situated within the field vocational education for young people and adults alike. It is geared toward both research and action. That is, seeking to address the tasks, problems and issues that are specific to vocational education and its further development as an important sector of education. Vocational 
didactics is not a discipline in its own right. Instead, Mayen holds that it is a process defined by a perspective on matters of vocational education, and specific principles, concepts and methods that give it coherence. In the first part of this chapter it is proposed that vocational didactics, along with its intentions, principles and concepts grant an important place to the question of conceptualization. The second part illuminates all of this through describing and discussing two cases of work analysis and training design under a vocational didactics approach. Both cases emphasise the central importance of conceptualization in action and how it can be advanced.

The theme of work activities as being central to realising effective vocational education provisions is also exercised within chapter by Marc Durand and Germain Poizat entitled An activity-centred approach to work analysis and the design of vocational training situations. In their chapter (11) they present an activity-based theoretical framework for pursuing two key objectives. These are, firstly, to understand the social practices of work and training, and, secondly, to inform the design of innovative vocational training methods. It is part of a tradition of inquiry and research that has come to be known as 'French ergonomics'. In this tradition, the analysis focuses on the articulation of work prescription and real work. Work prescription encompasses the set of explicit and implicit instructions in job specifications, as well as the constraints linked both to organising production and to management, further by going beyond the task analysis of the Anglophone approach. These prescriptions encompass and contribute to specifying the work objectives and the social and materials conditions for their accomplishment in through work. In contrast, real work is what workers actually do when they work. It is a type of human activity, which is conceptualised as a holistic theoretical object that can account for the individual and collective meaning and organisation of vocational practices and their transformations. The first part of the chapter presents an approach to work and vocational training that centres on the analysis of human activity. It falls within the theoretical framework of course-of-action, which is based on the postulate of enaction. Excerpts of actual cases are used to illuminate the theoretical premises, all of which are taken from enquiries into work and training in a variety of work settings. In the second part, the authors describe the procedural aspects of this research tradition. They also present the notion of spaces for encouraged actions as an instrument for training interventions in connection with an elaboration of hypotheses and theoretical elements mentioned above. In their conclusion, Durand and Poizat propose wide ranging purposes for which work analysis could be directed in the field of training.

Sylvie Ouellet and Nicole Vézina use a specific work context to elaborate the contributions of the ergonomic approach in that chapter (12) entitled Activity analysis and workplace training: an ergonomic perspective. Drawing upon the research in Frenchspeaking communities in Canada, they claim that when companies need to provide training, experienced employees are most often given the task of passing on their skills, which have largely been acquired through practice. These skills relate to performance of the work activity (e.g. movements, sensorimotor perception, planning), the characteristics of the material to be processed, the tools used, and working conditions that need to be taken into account. Yet, many authors report the difficulties that workers have in articulating (i.e. describing and formalizing) their working methods when questioned about them. This, of course, raises questions about how effectively of the passing on of 'know-how' occurs during training courses. It follows therefore that this chapter discusses and demonstrates how ergonomic 
analysis of a manual work activity was able to make accessible trade skills stored as "embedded knowledge" so that they could be incorporated into the content of training. Minute analysis of working movements, followed by clarification meetings, illuminated and identified the reasoning underlying movements and mental reference points that workers call upon to attain production and health-preservation objectives.

Laurent Veillard's chapter focuses on the conception of alternance in French tertiary education. Since the end of the eighties, 'alternance' training courses, consisting in combining and sequencing learning experiences in an educational institution with those in workplaces, developed quite well in France, especially at tertiary level. Consistent with these training aims, an important pedagogical question about this type of course is how to organise the workplace learning phases to optimise effective learning opportunities. A possibility is to develop a pedagogical partnership between the training and working institutions in order to take into account both the workplace learning specificities and the pedagogical aims and organisation of the training course. In his chapter (13) entitled, University-corporate partnerships for designing workplace curriculums: the case of a French work-integrated training program at tertiary level - Veillard addresses this issue within the specificities of the French educative context, where the vocational education system is historically mainly based on school teaching situations. Historical factors, institutional arrangements can be used to explain why the workplace learning culture is still weak in France comparatively to others countries like Germany, Switzerland or Australia. However, proposed here are ideas from both Francophone and Anglophone concepts that can assist in considering and organising pedagogical collaborations between scholar (or academic) and productive institutions. Based on these concepts, two case-studies in a master course (in production management) are used to illustrate different aspects and issues of such collaborations to organise workplace learning between a tertiary institution and two of its professional partners. The final part of the chapter is dedicated to a more general discussion, from the findings of the two case-studies and other additional studies, on the ways of improvement of this type of collaboration in the Francophone world.

Recent literature in the field of workplace learning has stressed the importance of guidance in the process of learning in and from practice. Workers do not only learn just by conducting specific tasks individually; they learn when adequate resources are afforded to them and when more experienced workers are able to assist them in their practice. Hence, in their chapter (14), entitled - Learning through verbal interactions in the workplace: the role and place of guidance in vocational education and training Laurent Filliettaz, Isabelle Durand and Dominique Trébert propose that there is considerable importance in elaborating the specific qualities of guidance at work and understanding how novice workers engage with these resources. In this particular context, the chapter advances two main considerations. The first is that a close examination of the conditions under which mentors and students engage in face-to-face interactions provides a relevant theoretical basis for exploring the relational interdependences between these actors. These interdependences may be described and analysed as "interactional participatory configurations". The second consideration advanced here is that recent research in the Francophone world provides useful insights for investigating these issues. It does so by borrowing concepts from a wide range of disciplinary traditions, such as anthropology, sociology, sociolinguistics and discourse analysis. These resources, it is proposed, offer complementary contributions to the understanding about the 
processes of participation and guidance in vocational and professional learning as it occurs in the workplace. Transcripts of video data collected in the field of vocational training of earlychildhood educators are used as empirical illustrations of the proposed analytical frame.

The chapter by Etienne Bourgeois, Julie Allegra and Cecilia Mornata (15), entitled Transmission and individuation in the workplace, aims at better understanding what conditions and through what processes does transmission in a given occupation allow for individuation (instead of mere reproduction)? To put it simply, individuation is to be understood here as the process through which novices in a given occupation gradually find their own personal way of thinking and doing things while incorporating the knowledge and practices being transmitted to them by the reference model. This view is based mainly on the French concept of "subjectivation”, as elaborated by Richard and Wainrib. In educational contexts, individuation implies some gradual detachment of learners from the reference expert model at four levels: i) cognitive, ii) behavioral, iii) affective, and iv) related to identity. The chapter examines the role of "macro" factors (i.e. related to the nature and evolution of the profession itself and its context) and "micro" factors (i.e. related to learners' interactions with their trainers and peers). This discussion is based mainly on two exploratory studies currently conducted at the University of Geneva. The first study focuses on the transmission process with experienced farmers who are converting to organic farming in Belgium and in France. This study highlights mainly "macro" factors of individuation. The second study deals with transmission in the context of students enrolled in a university master's degree program in developmental psychology. This second study highlights primarily "micro" factors of individuation.

Simone Volet provides an overview of this second section entitled - On the articulation of training and work: insights from Francophone research traditions. Her chapter (16) examines the conceptualisation of work activity that forms the foundation of Francophone perspectives on training and work, and reviews empirical work grounded in these perspectives. The chapter commences by identifying and discussing the three fundamental assumptions about the nature of work activity and workplaces as legitimate sites of learning and training that underpin Francophone research related to the articulation of training and work: i) actual work activity cannot be reduced to the prescribed task; ii) any work activity includes a productive and a constructive component; and iii) work activity affords the creation of rich learning opportunities for improved practice. The six empirical studies that have addressed the above assumptions are illustrated and scrutinized with reference to other bodies of literature concerned with workplace learning. Also identified across studies from the Francophone research traditions are common innovative methodological aspects of research. The final section of the chapter elaborates novel contributions of Francophone research. The aim here is to enhance the links between these contributions and the overall body of literature on learning through and for practice. She proposes that by conceptualising work activity and professional practices as enabling environments for training within the complexity of real-life, interactive and dynamic situations, and providing empirical support for this claim, research from Francophone research traditions makes a unique contribution to the literature on workplace learning, and also that on vocational, professional and training research. It is also claimed that the dissemination of this work in the Anglophone research community offers fresh possibilities 
for cross-fertilisation and mutual enrichment, conceptually, methodologically and educationally.

The concluding chapter (17) in this edited monograph by Stephen Billett, Raymond Smith and Charlotte Wegener is something of a reprise. Entitled - Understanding learning for and through work: Contributions from Francophone perspectives - it offers a discussion on what the chapters adds to the field of workplace learning through the accounts of Francophone traditions and conceptions of learning through and for work, and the practices they report used to understand more fully these processes of learning. It identifies and elaborates from an Anglophone perspective four distinctive qualities of the contributions within this edited monograph. These are, firstly, that there is no single or unitary Francophone tradition or conception of learning through practice. This quality is highlighted through outlining something of the diversity of what constitutes Francophone perspectives and some accounting of the origin of these distinct conceptions. The case made is that although there are cultural and linguistic traditions across the Francophone world, there are also localised historical and cultural factors that promote difference and diversity within these accounts. Secondly, and regardless there is an emphasis across the contributions on physically, socially and personally situated activity which stands as being distinct within Francophone accounts. This situatedness goes beyond an objective analysis of work-in-action in specific physical and social contexts (actions of workers), to include the situated nature of how individuals come to engage with what is being manifested in that context (e.g. how and on what bases they act). Thirdly, there is a pattern of contributions considering the worker as the person not only as an active and critical meaning-maker, but also through their bodily engagement within and to account for the consequences of their work. Further, that these focusses on the personal stand as being the point of analysis in some of the contributions that make this emphasis quite distinct. Fourthly, the means for understanding and organising support for learning through work seem distinct. The two sets of qualities just above suggest that traditions of professional didactics and ergonomics, in particular emphasis the situation and body, and seem quite culturally-distinct. They seem more analogous to laboratory and encounter sessions from the Anglophone world than what would be used in that world to organise work-based learning experiences. It is these four conceptions that are discussed in terms of what they contribute to the field of work and learning.

\section{References}

Billett, S. (2001). Learning in the workplace: Strategies for effective practice. Crows Nest: Allen and Unwin.

Clot, Y. (1999). La fonction psychologique du travail. Paris: Presses universitaires de France.

Clot, Y. (2008). Travail et pouvoir d'agir. Paris, Presses universitaires de France.

Gonon, P. (2009a). 'Efficiency' and 'Vocationalism' as Structuring Principles of Industrial Education in the USA Vocations and Learning: Studies in vocational and professional education, 2(2), 75-86.

Gonon, P. (2009b). The quest for modern vocational education: Georg Kerschensteiner between Dewey, Weber and Simmel (Vol. 9). New York: Peter Lang.

Pastré, P., Mayen, P., \& Vergnaud, G. (2006). La didactique professionnelle. Revue Française de Pédagogie, 154, 145-198. 
Rabardel, P. (1995). Les hommes et les technologies: une approche cognitive des instruments contemporains. Paris: Armand Colin.

Theureau, J. (2004). Le cours d'action. Méthode élémentaire. Toulouse: Octarès.

Theureau, J. (2006). Le cours d'action. Méthode développée. Toulouse: Octarès.

Tynjälä, P. (2008). Perspectives into learning at the workplace. Educational Research Review, 3, 130-154. 